\title{
O cuidado do hospital psiquiátrico decifrado pelo discurso de seus profissionais
}

\author{
The care of a psychiatric hospital deciphered by its \\ professionals' discourses
}

\author{
Allan Arruda* \\ Mikael Brasil** \\ Taíse Araújo*** \\ Petrônio Martelli****
}

\begin{abstract}
Resumo - Este estudo qualitativo analisou como profissionais do Hospital Psiquiátrico Ulysses Pernambucano (HUP) - estrutura assistencial de referência na Rede de Atenção Psicossocial (Raps) em Recife avaliam que seus conceitos assistenciais influenciam suas práticas. Foram selecionados cinco profissionais representantes de áreas disciplinar-acadêmicas distintas: psiquiatria, psicologia, enfermagem, técnico de enfermagem, serviço social. Com isso, foram realizadas entrevistas semiestruturadas com cada sujeito, com posterior análise dos conteúdos obtidos. Os profissionais entrevistados concordam que ideias influenciam práticas em saúde mental e que fundamental a esse processo é o entendimento da origem de suas formações. Assim, foi apontado que as ideias norteadoras do cuidado no espaço do HUP ora estão em confluência com os ideais da reforma psiquiátrica brasileira e suas legislações, ora se identificam com concepções tradicionais e obsoletas. Logo, uma das maiores lacunas na busca pela preservação do bem-estar do indivíduo adoecido demonstra ser derivada da falta de entendimentos balizadores consensuais.

Palavras-chave: saúde mental; assistência à saúde mental; hospitais psiquiátricos.
\end{abstract}

\begin{abstract}
This qualitative study analyzed how professionals of the Ulysses Pernambucano Psychiatric Hospital (HUP) - a renowned care unit in the Psychosocial Care Network in Recife, Pernambuco evaluate that their care concepts influence their work. Five professionals representing different academic-disciplinary areas were
\end{abstract}

\footnotetext{
* Graduação em Medicina pela Universidade Federal de Pernambuco (UFPE). $2^{\circ}$. tenente médico do exército brasileiro. E-mail: arruda.m.allan@gmail.com. ORCID: https://orcid.org/0000-0001-9568-940X.

** Mestrado em Saúde Coletiva pela Universidade Federal de Pernambuco (UFPE). Enfermeiro da prefeitura da cidade do Recife. E-mail: mikaelcpc@gmail.com. ORCID: https://orcid.org/0000-0002-2006-6934.

*** Graduação em andamento em medicina pela Universidade Federal de Pernambuco (UFPE). E-mail: taise. mca@gmail.com. ORCID: https://orcid.org/0000-0001-8816-2394.

**** Doutor em Saúde Pública pelo Instituto Aggeu Magalhães (FIOCRUZ). Professor associado da área acadêmica de Saúde Coletiva e pesquisador nas áreas de política, gestão e planejamento. E-mail: petroniocarla@uol.com.br. ORCID: https://orcid.org/0000-0001-6920-6435.
} 
selected: psychiatry, psychology, nursing, nursing technician, and social service. Semi-structured interviews were conducted with each subject, with subsequent analysis of the contents. The interviewed professionals agree that ideas influence mental health practices and that the understanding of their training's origin is fundamental to this process. Thus, it was pointed out that the guiding ideas of care in the HUP space sometimes agree with the ideals of the Brazilian Psychiatric Reform and its legislation, other times with traditional and obsolete conceptions. Therefore, one of the biggest gaps in the search for preservation of the well-being of sick individuals demonstrably arises from the lack of consensus in guiding principles.

Keywords: mental health; mental health Care; hospitals, psychiatric.

\section{Introdução}

Ao fazer uma análise temporal acerca da evolução das práticas em saúde mental, observa-se que elas estiveram e estão intimamente ligadas ao ideário vigente à época. Nesse sentido, Foucault (2004) assinala que, desde seu princípio, a psiquiatria esteve refém do conjunto de valores sociais, ainda que tida como disciplina puramente científica. Sendo assim, ela surgiu num contexto de ascensão burguesa em que havia a necessidade pela produção, bem como pelo redirecionamento ou exclusão do não produtivo. Portanto, aparece como pacto social identificando o dito "louco" e confinando-o à estrutura asilar em cenários negligentes, sem a consideração de critérios de adoecimento ou de possibilidades terapêuticas (FOUCAULT, 2004).

Em seguida, uma vez que a ideologia hegemônica é fluida e inconstante, o surgimento de novos juízos acompanhou também novas formas de pensar a saúde mental e seu cuidado. De forma mais dramática, o momento mundial pós-Segunda Guerra suscitou olhares ainda mais transformadores sobre a realidade asilar, o que refletiu nas diversas nacionalidades dos diferentes movimentos de reforma psiquiátrica (FOUCAULT, 2004).

Em território brasileiro, o verdadeiro gatilho para esse processo foi o momento pós-ditatorial junto à grande revolução de pensamentos, os quais culminaram em tantos outros movimentos com o sentido democrático e de bem-estar social. Assim, baseada nas ideias do italiano Franco Basaglia e apoiada principalmente no movimento de trabalhadores de saúde mental (MTSM), a reforma psiquiátrica brasileira irrompeu, a partir da redação do Manifesto de Bauru de 1987, síntese do ideário reformista brasileiro (AMARANTE, 1998). Desde então, muito foi construído a partir desses ideais, sendo consolidado principalmente em dois dispositivos legislativos: a Lei $\mathrm{n}^{\circ}$ 10.216/2001, conhecida como Lei da Reforma Psiquiátrica; e a Portaria Raps de 2011, que instaura e dispõe acerca dos componentes da Rede de Atenção Psicossocial (Raps), ambas distanciando-se do modelo asilar de cuidado e fortalecendo a potencialidade social do indivíduo adoecido (BRASIL, 2001; 2011). 
Entretanto, como pontuado, as ideias outrora preponderantes não são conclusivas, mas estão em contínua renovação e são dependentes do sentimento de época. Ana Pitta (1996), por exemplo, há muito havia trazido a observação de heterogeneidade de valores e significados que ganha o termo na tradição brasileira. A autora discute, inclusive, distinções geográficas significativas ao explorar abertamente a prática terapêutica em diversas cidades específicas. Dessa forma, a autora conclui que, desde que ganhou o status de democracia emergente, o Brasil conta com movimentos em saúde mental que conjugam uma direção a pensamentos atrelados a preceitos da reforma psiquiátrica, mas significativamente distintos em prática epistemológica (PITTA, 1996).

Considerando que concluir uma definição ao termo sempre encontrará barreira em concepções subjetivas, a reabilitação psicossocial figura no modelo da Raps como um de seus componentes ativos, e garante como conceito básico ao descrever:

[...] iniciativas de geração de trabalho e renda/empreendimentos solidários/cooperativas sociais de que [...] devem articular sistematicamente as redes de saúde e de economia solidária com os recursos disponíveis no território para garantir a melhoria das condições concretas de vida, ampliação da autonomia, contratualidade e inclusão social de usuários da rede e seus familiares. (BRASIL, 2011, n. p.).

Assim, a Portaria Raps de 2011 parece entrar de acordo com a concepção de promoção de saúde multifatorial, sob uma lógica de integrar a fim de potencializar (BRASIL, 2011).

Considerado isso, vemo-nos diante de um novo momento de especial efervescência ideológica com fortalecimento da lógica neoliberal e tendências retrógradas às políticas públicas firmadas. No contexto da saúde mental, isso vem tomando forma peculiar ao apontar para o retorno de princípios não reformistas e práticas centradas em modelos hospitalares (SOUZA; JORGE, 2019; GUIMARÃES; ROSA, 2019). Entretanto, ainda por disposição em Portaria Raps, a figura do hospital psiquiátrico só é prevista em cenários locais em que o processo de substituição de leitos psiquiátricos por outros dispositivos não tenha sido efetivado, tornando a rede dependente de sua atividade (BRASIL, 2011). Infelizmente, essa realidade em nível nacional não se mostra exceção, mas amplamente comum devido aos muitos vazios assistenciais existentes, ou seja, municípios nos quais a oferta de leitos não é suficiente para atender a população (PITTA, 2011).

Dessa forma, o município do Recife se apresenta como exemplo desse cenário descrito, no qual a presença do histórico Hospital Ulysses Pernambucano (HUP) se faz marcante. Principalmente como resultado da falha na descentralização do cuidado, o hospital é amplamente entendido como fundamental ao atendimento de demandas em saúde mental não só 
a nível municipal, como estadual, uma vez que se dispõe como único serviço de emergência psiquiátrica do estado de Pernambuco (OLIVEIRA, 2008).

Portanto, considerando a junção de novos pensamentos hegemônicos e a difícil superação dos vazios assistenciais, pode-se depreender que o hospital psiquiátrico é uma realidade (forte) e de grande longevidade. Sendo assim, como seria possível antecipar as práticas de cuidado presentes em seu espaço, se seu funcionamento nem mesmo está previsto em portaria (BRASIL, 2011)? Ora, já entendida a influência das ideias sobre o cuidado, a identificação e análise dessas primeiras se mostra uma alternativa interessante. Partindo dessa premissa, outros estudos já conseguiram estabelecer essa mesma correlação, trazendo conclusões esclarecedoras dentro de seus contextos próprios (MIELKE et al., 2009; BALLARIN et al., 2011; ZGIET, 2013).

Num contexto político de obscurantismo e retrocesso no tocante às conquistas sociais - aí inclusa a reforma psiquiátrica -, este trabalho propõe identificar as ideias de cuidado ativas no espaço do Hospital Psiquiátrico Ulysses Pernambucano a partir de seus profissionais, ao mesmo tempo que busca avaliar sua proximidade com a lógica reformista.

\section{Percurso metodológico}

Este trabalho' se caracteriza por ter natureza qualitativa e ser um estudo do tipo exploratório, com limite espacial ao Hospital Ulysses Pernambucano (HUP) e espaço temporal de realização entre agosto de 2018 e julho de 2019.

O desenvolvimento do estudo se deu com a participação de profissionais da atenção psicossocial especializada do HUP, definidos a partir da identificação de sujeitos mais familiarizados com as discussões propostas. Dessa forma, optou-se pela definição de cinco sujeitos, cada um representando uma área disciplinar-acadêmica, havendo profissionais de: psiquiatria, psicologia, enfermagem, técnico de enfermagem e serviço social. A proposta de seleção de indivíduos parte da premissa de trabalho em equipe no ambiente hospitalar, bem como da possibilidade de origens diferentes gerarem olhares diferentes.

Dessa forma, com uma seleção intencional e qualificada, foram estabelecidos os sujeitos a serem estudados. A contribuição dos mesmos foi obtida a partir da realização de entrevistas semiestruturadas individuais e orientadas por roteiro previamente definido, o qual continha questionamentos referentes ao processo de cuidado na instituição psiquiátrica como dispositivo do cenário da atenção psicossocial de Pernambuco. As entrevistas foram registradas em gravador simples após a devida apresen-

\footnotetext{
'Sua aprovação se deu mediante submissão à avaliação pelo Comitê de Ética em Pesquisas do Centro de Ciências da Saúde da Universidade Federal de Pernambuco com Parecer $n^{\circ} 3.110 .295$, registrado sob Caae 01617018.9.0000.5208.
} 
tação de suas implicações éticas, com apresentação e assinatura de Termo de Consentimento Livre e Esclarecido (TCLE).

Dando seguimento, foi realizada a transcrição das entrevistas gravadas, que puderam ser avaliadas a partir da análise do conteúdo, seguindo o método de Laurence Bardin (2011). Bardin (2011) propõe a avaliação de mensagens como um ato simultâneo de atuar como receptor direto da comunicação e de deduzir novos entendimentos latentes intrínsecos. Como canal viabilizador, inicialmente, o software de análises estatísticas em linguagem Iramuteq foi eleito para o reconhecimento de grupos de palavras e termos repetitivos dentro das temáticas avaliadas. A partir da leitura oferecida pelo software, que contemplou o aparecimento de termos preponderantes, como "rotina", "cuidado", Caps, rede, entre outros, foi possível identificar concepções comuns aos discursos para, enfim, serem alcançados os objetivos do trabalho.

Para a apresentação do material produzido, optou-se por mostrar trechos de relevância entre as falas dos profissionais entrevistados, culminando em três categorias, a fim de apropriar a discussão à subjetividade íntima dos mesmos e possibilitar a imersão do leitor. Tais trechos aparecem com grifo - reforçando seu anonimato - recebendo identificação de autoria pelos vocábulos: P1, P2, P3, P4 ou P5, estando sua ordem numérica estabelecida a partir de nenhuma lógica em particular.

\section{O espaço do hospital psiquiátrico na rede}

De início, a fim de entender o papel do hospital psiquiátrico na visão dos profissionais entrevistados, dois questionamentos principais foram sugeridos: qual a função propriamente dita do hospital e qual o seu diferencial em relação aos demais dispositivos da Raps.

Ironicamente, a opinião mais forte entre os discursos indicou uma função substitutiva do hospital psiquiátrico, ou seja, um encargo não prioritário no oferecimento de outros serviços que fogem ao seu escopo assistencial, ainda que atribuído grande valor de relevância. Assim, para a maioria dos profissionais, o hospital aparece como alternativa terapêutica frente a situações de pouca adequação da rede em relação às demandas locais apresentadas.

Dissecada a cru, essa ideia estaria de acordo com a Portaria Raps de funcionamento do hospital psiquiátrico ao considerar que ele pode ser acionado enquanto o funcionamento e a expansão da Raps em determinadas regiões de saúde se mostram insuficientes (BRASIL, 2011). Entretanto, o mesmo trecho ressalta que essas mesmas regiões devem priorizar a expansão e qualificação da rede a fim de dar curso ao processo de substituição de leitos psiquiátricos (BRASIL, 2011). Sendo assim, tal cenário se apresentaria com caráter temporário e de exceção, não predominância. 
Apesar disso, o que se percebe com a análise mais profunda das falas é justamente o oposto, tendo o seu conteúdo apontado para uma dependência vitalícia da rede da figura do hospital psiquiátrico, visto que há estado de insuficiência crônica dos dispositivos substitutivos. Esse cenário parece reproduzível em diversos outros contextos nacionalmente, o que Ana Pitta (2011) viria a chamar de vazios assistenciais, ao analisar o saldo reformista mesmo após uma década de homologação da Lei $n^{\circ} 10.216$ (BRASIL, 2001).

Na verdade, a gente é o terciário... Na verdade, a gente deveria ser o último a ser procurado. Mas na verdade, a gente é o primeiro. [...] Então, atualmente a gente oferece pra rede... tudo! (P5, sobre o hospital psiquiátrico).

Dessa forma, sugere-se o papel do hospital psiquiátrico como instituição de primeiro momento de cuidado, principalmente diante de quadros de vulnerabilidade mais desafiadores, sendo responsável por uma "estabilização" inicial seguida de redirecionamento aos demais componentes da rede. Seguindo essa lógica, os pontos apresentados como distinções vantajosas do hospital psiquiátrico acabaram por se apresentarem como próprios reflexos do que é visualizado como deficiente nos demais serviços da rede - pelo menos em contexto local - sendo os Caps usados como fonte maior de comparação.

Os hospitais psiquiátricos ainda existem porque são necessários. A rede de assistência que seria substitutiva ao hospital psiquiátrico, os Caps, por exemplo, associados a ambulatório etc., eles não estão suprindo a demanda. (P4).

A princípio, mostrou-se preponderante a possibilidade de terapêutica continuada, em ritmo diário, por equipe de saúde dentro do espaço do hospital psiquiátrico contra o cuidado aparentemente fragmentado oferecido pelo Caps cotidianamente. Ainda, foi alegado que a própria terapêutica descontinuada e/ou limitada dos Caps acabaria por suscitar estados de maior vulnerabilidade psíquica, que levariam os próprios serviços a acionar o hospital. Assim, as principais razões proferidas que justificariam a tal fragmentação no cuidado no espaço do Caps foram: a ausência de profissionais habilitados em saúde mental diariamente; e a falta de recursos terapêuticos, em especial as medicações psiquiátricas.

É uma rotina. Aí, eu acredito que a rotina faz o que um Caps não faz. Porque, por exemplo, o Caps vai depender da vontade do paciente, vai depender de a família querer ajudar o paciente... (P1, sobre a terapêutica em hospital psiquiátrico). 
Outro diferencial que chamou atenção entre os discursos se refere à chance de um espaço físico-estrutural mais preparado para a contenção de agudização de crises psiquiátricas, a saber: grades, medicações injetáveis e contenção física compulsória. Ora, considerando Caps e demais serviços substitutivos oriundos da lógica de reforma psiquiátrica e voltados para a valorização da autonomia e cuidado humanizado (BRASIL, 2001; 2011), faz-se lógico pensar em ambientes não programados para este fim. Além disso, entende-se o surgimento dos Caps como uma proposta que respondesse às novas demandas de desinstitucionalização do cuidado, mas com sua efetivação tão limitada quanto à aspiração de quem o conduz. Ou seja, a simples existência de serviços substitutivos (Caps) não impede a institucionalização do indivíduo ou mesmo de reprodução de práticas manicomiais (FACUNDES, 2010).

Apesar de essa consciência ter estado presente em meio ao conteúdo dos entrevistados, a consideração da existência de situações de maior complexidade - envolvendo principalmente heteroagressividade - mostrouse suficiente para superar a teoria e justificar a necessidade dessas ferramentas na prática diária. Nessa lógica, Zgiet (2013) observou a frustração de trabaIhadores tanto dos Caps quanto do hospital psiquiátrico ao esbarrar com as dificuldades do trato com a saúde mental sob a perspectiva da reforma psiquiátrica, a qual "exige inovação, criatividade e atitude" (ZGIET, 2013, n.p.).

Então, essa coisa da contenção física mesmo, no Caps a gente não faz. No Caps é muito corpo a corpo, muita conversa, 'vamos tentar', mas chega um momento que a gente não dá conta. (P3).

Seria assim: uma internação numa crise realmente muito aguda, e não teria como a rede dar suporte no momento, questões de vulnerabilidade do paciente, de agressividade... (P5, sobre a função do hospital psiquiátrico).

Além disso, o espaço hospitalar ainda foi apontado como vantajoso ao se considerar o componente estritamente orgânico da saúde, segundo a lógica biomédica de cuidado. Nesse sentido, o discurso defende que hospitais se apresentam mais equipados com profissionais e dispositivos de cuidado em clínica médica.

Outro ponto recorrente das discussões foi sobre o hospital psiquiátrico como canal de serviço de atendimento a emergências psiquiátricas. Isso estaria justificado como uma possibilidade de descentralização de serviços de emergências em geral, naturalmente sobrecarregados e pouco preparados com situações emergenciais em saúde mental.

Eu acho que só nesse sentido de urgência e emergência. Porque os outros serviços já... Várias coisas que tem aqui, tem no Caps. (P2, sobre o diferencial dos hospitais psiquiátricos). 
Então, os Caps têm nome de 24 horas, o Caps III, mas efetivamente não são, o que é uma contradição. (P4, sobre o argumento de serviços de emergência psiquiátrica).

Novamente, entra aqui o paradigma de funcionalidades integralmente previstas ao funcionamento dos Caps em sua modalidade $24 \mathrm{~h}$ (BRASIL, 2011), mas notadas de forma fragilizada pelos trabalhadores. Além disso, cabe lembrar que a Portaria Raps discorre acerca de um componente específico à "atenção de urgência e emergência", em que estabelecimentos de emergência geral deveriam ser parte do atendimento a demandas em saúde mental (BRASIL, 2011).

\section{Impacto do HUP sobre a Raps Recife}

Além de esmiuçar os entendimentos sobre hospitais psiquiátricos em geral, também foi procurado entender o impacto local do HUP - especificamente - sobre a rede recifense. Os resultados opinativos sobre o hospital recifense se apresentaram muito próximos às ideias já discutidas sobre a instituição hospital psiquiátrico em si. Foi unânime a reafirmação de uma necessidade primordial do HUP para suprir não apenas as demandas do município de Recife, como também de todo o estado de Pernambuco. Isso pode ser justificado pela presença basicamente unitária do hospital como serviço de emergência psiquiátrica no contexto público municipal e estadual (SILVA, 2015). Ainda assim, considerando sua apresentação tão peculiar à rede, algumas outras ponderações foram feitas ao HUP.

Eu acho que não tô nem te respondendo do Ulysses, né? Acho que tô te falando de hospital de uma forma geral... É porque o Ulysses é o único hospital que tem! (P3, frente ao questionamento da relação entre HUP e Raps Recife).

Importância... 100\%... Extrema! Não tem o que discutir. [...] Se não, não tinha paciente aqui, nem fila de espera lá na portaria. (P3, sobre a contribuição do HUP à Raps Recife).

Nessa perspectiva, foi indicada a necessidade de serem traçadas estratégias de descentralização das demandas hospitalares, sobretudo em contexto emergencial. Para tanto, sugeriu-se investimentos em estrutura e recursos tanto para o espaço do hospital psiquiátrico quanto para os demais dispositivos substitutivos.

Deveria ser melhor olhado pelos governantes. [...] Devia ter uma estrutura melhor, por ser um hospital muito importante pro estado. (P1, sobre o HUP). 
Aí, eu não sei se é o Caps que não tá dando conta, e por isso precisa de mais hospital; ou não devia ter hospital mesmo e um maior investimento nos Caps. Alguma coisa está errada no meio do caminho... (P3, sobre demandas em emergência na Raps Recife).

Esse ponto em específico parece evidenciar novamente a aparente inversão de valores institucionais ao se observar a figura do hospital - original e teoricamente apenas complementar (BRASIL, 2011) - como o maior ponto de "afogamento" em demandas.

Outrossim, a observação de dependência da Raps Recife à figura do HUP se mostrou visualizada com graus de preocupação quanto a sua longevidade. Devido ao recente histórico de fechamento progressivo de leitos psiquiátricos no município (MAIA, 2007; SILVA, 2015), os profissionais entrevistados se mostraram receosos com um futuro semelhante do HUP em meio a sua participação decisiva no cuidado emergencial em saúde mental local.

Apesar desse referido estranhamento, é de conhecimento basilar a disposição regulamentada do processo contínuo de substituição de leitos psiquiátricos (BRASIL, 2011), no sentido de ser um movimento natural a qualquer rede de saúde mental. Entretanto, a crítica feita foi a de que processos substitutivos deveriam ser acompanhados de um planejamento mais acurado e compatível com as necessidades de cada rede. Em outras palavras, uma programação gestora que garantisse a tradução de demandas hospitalares em outros serviços de forma efetiva. Sobre isso, Goulart e Durães (2010) haviam mencionado que o processo de desinstitucionalização é diretamente ligado às variáveis microssociais locais, dependente de suas interações e disputas.

[...] o Ulysses vai continuar existindo enquanto tiver demanda pra ele. [...] Ainda falta muito. Eu acho que [a rede] tem que melhorar muito enquanto ele existe. (P4).

Eu ia ficar feliz se tivesse uma rede que tivesse esse suporte. Porque se você conversar, a maioria dos nossos colegas aqui torce para que tenha a reforma [psiquiátrica]. Agora, que seja uma reforma digna. [...] Tem que melhorar muito. (P5, sobre a efetivação dos ideais reformistas em rede).

Curiosamente, esse receio ainda foi apontado pelos profissionais como vigorosamente presente entre diversos usuários (e seus familiares) do hospital. Isso estaria presente ainda com mais força em quadros psicossociais de maior vulnerabilidade, onde o espaço do hospital muitas vezes se configura como uma oportunidade de primeiro cuidado.

[...] eu vejo muitos pacientes tendo uma transferência maravilhosa com o hospital, que adora isso aqui. Vários pacientes que vem pra 
cá, e não quer sair daqui não. [...] Se um hospital tá melhor do que tá em casa, é porque tá complicado. (P2, sobre o HUP).

Eu já escutei várias famílias dizendo: 'Se fechar isso aqui, como é que vai ser?'. A gente escuta dia a dia. É preocupante. (P5, sobre um possível encerramento das atividades do HUP).

\section{Influência das ideias sobre o cuidado}

Finalmente, a culminância dos questionamentos apresentados se direcionou mais uma vez a um olhar introspectivo. Sob essa perspectiva, os entrevistados foram questionados acerca de como observavam suas ideias pessoais influírem em suas práticas terapêuticas.

Nesse panorama, todos os profissionais admitiram a existência da relação ideais-cuidado em suas atividades em saúde. Isso estaria ainda mais fundamentado no campo da saúde mental, no qual até mesmo a origem das formações pessoais foi apontada como decisiva. Reis e Guareschi (2010) trouxeram essa discussão ao observar a formação profissional de psicólogos como pilar fundamental de suas práticas, e absolutamente atreladas ao contexto político em que se deram.

[...] se for por uma lógica manicomial, você vai produzir não só o cuidado, mas a própria loucura que vai aparecer [...]. A forma que o profissional é formado, é forjado, diz do cuidado que ele vai oferecer aos pacientes. (P2, sobre ideias influenciando o cuidado em saúde mental).

Partindo do pressuposto de que as formações dos profissionais são determinantes na terapêutica oferecida, fez sentido a observação do efeito coletivo desse fenômeno em nível hospitalar, isto é, da multiprofissionalidade e/ou interprofissionalidade. Segundo a discussão dos termos trazida por Alvarenga et al. (2013), multiprofissionalidade diz respeito ao arranjo paralelo de diferentes disciplinas, que por muitas vezes pode levar a um processo fragmentado de cuidado; enquanto que interprofissionalidade estaria mais ligada à ideia da construção conjunta de decisões através do entendimento mútuo.

Dada a discussão semântica desses dois conceitos de trabalho em equipe de saúde, os discursos obtidos pareceram pendular entre ambos. Enquanto parte dos conteúdos trouxe à tona a crítica de um cuidado fragmentado entre os diversos saberes, outros indicaram a confluência das formações como algo positivo ao cuidado integral.

Às vezes, eu me sinto a formiguinha: eu executo, mas a minha ideia, o meu raciocínio clínico, ele não é compartilhado. Porque a gente 
não tem uma reunião pra compartilhar. (P3, sobre trabalho em equipe multiprofissional no HUP).

[...] cada um tem uma visão. Então, a gente construiu um projeto. E do projeto, o paciente serve pra rua. E o projeto influencia. Então, dá pra nota no dia a dia que faz diferença. [...] Um vai complementando o outro. [...] Como se fosse uma roda de segurar a mão, que fala na mesma língua. (P5, sobre interdisciplinaridade no HUP).

Ainda refletindo sobre a influência das formações nos profissionais da saúde mental, foi possível depreender observações que extrapolavam a noção de equipe multiprofissional sob a lógica disciplinar-acadêmica. À vista disso, a presença de outros profissionais de função operacional - a princípio não considerados próprios da saúde mental -, como vigilantes e porteiros, foi apontada como definitiva ao resultado do cuidado oferecido no HUP. Partindo do pressuposto de que, frequentemente, esses profissionais estariam em contato orgânico ainda mais próximo no convívio com os usuários do hospital, as trocas produzidas seriam decisivas na vivência terapêutica. Além disso, a possível origem sociocultural mais próxima entre ambos os sujeitos facilitaria essa conexão.

[...] o vigilante falou que o paciente chegou e disse: 'Converse comigo, que eu quero me cortar muito aqui' [...]. Veja, eu vou dizer que uma pessoa dessas não faz parte da equipe? Com certeza faz.

Muitas vezes, quem faz o acolhimento é muito mais esses profissionais que a gente. Quem recebe as famílias dos pacientes na portaria dos hospitais nas ruas é o porteiro. (P2, sobre a influência de profissionais operacionais na terapêutica do HUP).

Por conseguinte, mais importante do que a mera presença de tais profissionais no ambiente hospitalar seria, novamente, sua formação pessoal. Aqui, ressaltamos que envolvemos na ideia de formação conceitos que vão muito além do academicismo, mas de desenvolvimento das identidades, incluindo noções culturais. Nesse sentido, Câmara et al. (2012) falaram da importância em incluir um enfoque coletivo na educação permanente que aborde o conceito ampliado em saúde, ao entrevistar profissionais de uma unidade básica de saúde, incluindo em seu escopo - entre outros profissionais - porteiros e auxiliares administrativos.

Por esse ângulo, os entrevistados reafirmaram a psicoeducação e sensibilização desses outros profissionais (vigilantes e porteiros) como parte fundamental do cuidado produzido no ambiente hospitalar. Em outras palavras, a própria equipe especializada da atenção psicossocial demonstra reconhecer não só a influência das ideias sobre o cuidado em saúde mental, mas sua responsabilidade em oferecer subsídios para direcionar possibilidades terapêuticas positivas. Essa observação parece estar de acordo 


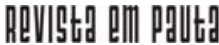

\} O CUIDADO DO HOSPITAL - ARRUDA, A.; BRASIL, M.; ARAÚJO, T.; MARTELLI, P. \}

DOI: $10.12957 /$ REP.2022.63444

com achados prévios em que as formações profissionais e a educação permanente aparecem como elementos fundamentais na constante reflexão e problematização das práticas em equipes de saúde mental (MEDEIROS et al., 2016; SCAFUTO; SARACENO; DELGADO, 2017). Além disso, Leite e Rocha (2017) avaliam que as conexões entre diferentes profissionais e práticas em espaços de educação permanente em saúde potencializam perspectivas transformadoras.

\begin{abstract}
Vinte anos num hospital psiquiátrico e não sabe o que é um delírio? É assustador. [...] Então, o vigilante precisa saber o que é um Caps, o que é saúde mental [...]. Os profissionais têm que estar envolvidos, precisam estar inseridos nessa lógica, de que clínica é essa. (P2, sobre psicoeducação de todo o corpo profissional do hospital psiquiátrico).
\end{abstract}

Psicoeducar também a equipe de trabalho. É sempre importante fazer isso também. Pra dar um tratamento mais humanizado pro paciente, à família dele. (P4, sobre contribuição da equipe especializada à psicoeducação dos demais profissionais).

Em outra instância, os entrevistados ainda reconheceram a influência dos ideais sobre seus trabalhos numa perspectiva em que ambos se acompanham em perspectivas dinâmicas. Desse modo, ao longo de suas vivências, houve a percepção de que novas formas de pensar sobre o indivíduo adoecido levam a novas práticas terapêuticas. Isso se mostrou ainda mais presente naqueles com maior tempo de atuação profissional no HUP.

Uma vez entendida a relativamente recente mudança do paradigma brasileiro em saúde mental (AMARANTE, 1998), é lógico que o impacto do ideário da reforma psiquiátrica tenha sido mais sentido por aqueles que acompanharam seu processo. Nesse sentido, observa-se o espaço do hospital psiquiátrico como um dos mais afetados, seja pelo fechamento progressivo dos leitos, seja pelo novo norte do cuidado intra-hospitalar (GOULART; DURÃES, 2010). Essa realidade inserida ao contexto do HUP foi percebida no conteúdo das falas como o surgimento de um cuidado mais humanizado e de períodos mais breves. Essa observação parece estar alinhada com o teórico disposto pela Lei $n^{\circ}$ 10.216/2001 ao redirecionar o modelo assistencial em saúde mental, reforçando a proteção e direitos das pessoas portadoras de transtornos mentais (BRASIL, 2001).

[...] [eu] não saio de casa só pensando em medicar, eu saio de casa pensando em cuidar de um paciente, em ver ele melhor. (P1, sobre mudança em perfil de cuidado no HUP).

Até um tempo atrás o paciente era pensado como sendo um paciente do Ulysses. As famílias deixavam aqui. [...] Sendo que o paciente é pensado pra fora. $\mathrm{O}$ paciente não é nosso. (P2, sobre mudança em perfil de cuidado no HUP). 
Já não existe paciente abrigado no Ulysses como há anos atrás existia, que era o modelo manicomial. Isso não existe no Ulysses. (P4, sobre mudança em perfil de cuidado no HUP).

Quando eu cheguei aqui, tinha funcionário na internação que maltratava paciente. Paciente sendo agredido por funcionário há um tempo atrás. Então, era horrível, né? Só que influenciava, que eu achava que era normal. Aí, foi mudando... (P5, sobre mudança em perfil de cuidado no HUP).

Finalmente, esse processo de transição foi entendido como fluido, estando atrelado principalmente ao feedback obtido com práticas diárias. Assim, o cuidado em saúde mental do HUP estaria em constante reforma a partir das demandas que venham a surgir. Para tanto, seria necessário um contínuo de comunicação entre os profissionais (com suas ideias pessoais) e a gestão do hospital. Nessa concepção, Ballarin et al. (2011), ao trabaIharem a percepção de profissionais de um Caps, notaram que a noção de trabalho humanizado envolvia o compromisso contínuo em discutir a organização do próprio trabalho.

Inclusive, das mais recentes mudanças no funcionamento do hospital, a que tomou espaço de destaque em ser citada foi a chamada proposta do serviço de "clínica de articulação". Seguindo a lógica, os projetos terapêuticos traçados estariam intimamente ligados ao território de origem de cada usuário, estando a sua internação pensada em conjunto com o retorno aos demais dispositivos territoriais, de forma articulada.

Hoje, tanto que a lógica do hospital é trabalhar com essa articulação, que é pra isso: chegou, ele já tá com o pé na rua. A gente já tá articulando pra ele ir, retornar pra casa e pra comunidade. Continuar tratamento no Caps. (P5, sobre a proposta de clínica de articulação).

\section{Conclusões}

Com este trabalho, temos a síntese das convicções de parte do corpo profissional do HUP em relação a algumas das mais recorrentes e controversas questões da saúde mental coletiva. Os resultados aqui obtidos não só são produto de realidades observadas, mas também do conjunto de vivências de um grupo muito particular.

Seguindo essa lógica, os profissionais entrevistados demonstraram reforço à concepção de que ideais pessoais influenciam o cuidado produzido em saúde mental. Além disso, propuseram desdobramentos a partir dessa convicção, os quais podem ser aplicados a diversos outros entendimentos.

Uma das percepções que mais se destacou foi: tão ou mais importante do que quais ideias estão norteando práticas, são os caminhos 
que levaram à sua formação. Nesse sentido, as formações pessoais aparecem como ponto estratégico de reflexão no campo da saúde mental, uma vez que antecedem em nível primitivo a produção de cuidado. E por que não mesmo em nível presente, atuante, já que a formação humana não é processo finito? Dessa maneira, essa noção nos suscita o questionamento de como podemos intervir em formações profissionais de modo a apontar para ideias consensuais, voltadas ao coletivo e ao interesse público.

Além disso, podemos observar algumas pontuações interessantes sobre a noção de trabalho em equipe. Nota-se desejo por novas perspectivas, que permitam a coexistência síncrona de visões, bem como expandir sua lógica de atuação a outros sujeitos operantes no ambiente do hospital psiquiátrico. Assim, parece haver a aspiração por equipes que se comuniquem e ofereçam recursos para o próprio crescimento de seus personagens, inclusive, ao reconhecer o saber e poder terapêutico (ou tóxico) daqueles sem formação acadêmica - vigilantes, porteiros, auxiliares administrativos etc.

Já em termos das ideias em si, observa-se que os profissionais entrevistados admitem intenções próximas às da reforma psiquiátrica brasileira, origem da lógica da rede garantida até hoje. Assim, alguns dos pontos que entram em concordância são: a defesa do cuidado humanizado, centrado na pessoa e não na doença; internações mais breves possíveis; idealização do indivíduo em seu território. Em suma, a intenção geral parece ser o reforço da humanidade do indivíduo adoecido, ao passo que se oferece saúde.

Por outro lado, se o pensamento basilar dos profissionais do HUP está de acordo com aquele disposto em regulamentações, o caminho para alcançá-lo apresenta alguns desvios. Por exemplo, os próprios projetos de reabilitação psicossocial encontram-se ainda muito alinhados com concepções tradicionais e obsoletas, além de pouco consensuais entre si. Não obstante, a defesa por recursos e comportamentos historicamente associados à instituição asilar também se faz presente, como o uso de contenção física e/ou química e a menor valorização da autonomia.

Apesar disso, nenhum dos profissionais entrevistados apoiou abertamente a estrutura manicomial, mas sim a figura hospitalar, a qual é facilmente propensa a práticas institucionalizantes. Nessa lógica, a defesa do hospital psiquiátrico variou em argumentos, porém parece apontar para uma noção básica de necessidade maior em situações de maior agravo. Dessa maneira, a interação ineficaz com os demais dispositivos locais parece atuar de forma importante nesse entendimento. De toda forma, é evidente que esses profissionais ditos "da ponta" se mostram frustrados com a disposição dessa rede e clamam por mais recursos com que possam trabalhar, seja em ambiente intra ou extra-hospitalar.

Sendo assim, o que podemos observar são pessoas que desejam as mesmas coisas esperadas do bom profissional de saúde, em outras palavras, o gozo da saúde plena do indivíduo adoecido. O que parece destoar são os percalços técnicos do que levaria ao alcance dessa condição. À vista 


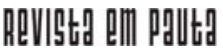

\} O CUIDADO DO HOSPITAL - ARRUDA, A.; BRASIL, M.; ARAÚJO, T.; MARTELLI, P. \}

DOI: $10.12957 /$ REP.2022.63444

disso, aparentemente falta o consenso de ideias entre os profissionais da saúde mental a fim de uniformizar práticas de valor terapêutico.

Em vez do reforço das diferenças entre grupos e de ceder à tentação de taxações simplistas, uma alternativa seria a de um diálogo sério com a comunidade profissional. Dessa maneira, a discussão da saúde mental poderia sofrer menos com a atual fragilidade dialética da sociedade brasileira, e ser mais reflexo daqueles que realmente a compõem. Afinal, profissionais do hospital psiquiátrico são, em última análise, profissionais da rede com contribuições e demandas potenciais à manutenção do projeto brasileiro de saúde popular. 


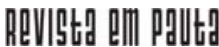

\} O CUIDADO DO HOSPITAL - ARRUDA, A.; BRASIL, M.; ARAÚJO, T.; MARTELLI, P. \}

DOI: $10.12957 /$ REP.2022.63444

\section{Referências}

ALVARENGA, J. P. O et al. Multiprofissionalidade e interdisciplinaridade na formação em saúde: vivências de graduandos no estágio regional interprofissional. Revista Enfermagem UFPE, n. 7, v. 10, 2013.

AMARANTE, P. Loucos pela vida: a trajetória da reforma psiquiátrica no Brasil. Rio de Janeiro: Fiocruz, 1998.

BALLARIN, M. L. G. S. et al. Percepção de profissionais de um Caps sobre as práticas de acolhimento no serviço. O Mundo da Saúde. v. 35, n. 2, 2011.

BARDIN, L. Análise de conteúdo. São Paulo: Almedina, 2011.

BRASIL. Lei n. 10.216, de 6 de abril de 2001. Dispõe sobre a proteção e os direitos das pessoas portadoras de transtornos mentais e redireciona o modelo assistencial em saúde mental. Brasília, Diário Oficial da União, 9 abr. 2001. Disponível em: http://www.planalto.gov.br/ccivil_03/leis/ leis_2001/l10216.htm. Acesso em: 6 jul. 2019.

BRASIL. Ministério da Saúde. Portaria n. 3088, de 23 de dezembro de 2011. Institui a Rede de Atenção Psicossocial para pessoas com sofrimento ou transtorno mental e com necessidades decorrentes do uso de crack, álcool e outras drogas, no âmbito do Sistema Único de Saúde. Brasília, Diário Oficial da União, 23 dez. 2011. Disponível em: http://bvsms.saude.gov.br/ bvs/saudelegis/gm/2011/prt3088_23_12_2011_rep.html. Acesso em: 6 jul. 2019.

CÂMARA, A. M. C. S. et al. Percepção do processo saúde-doença: significados e valores da educação em saúde. Revista Brasileira de Educação Médica, v. 1, n. 36, 2012.

FACUNDES, V. L. D. O discurso e a prática no Centro de Atenção Psicossocial: a construção do cuidado em saúde mental. Tese (doutorado em Neuropsiquiatria e Ciências do Comportamento) - Universidade Federal de Pernambuco, Recife, 2010.

FOUCAULT, M. História da loucura. São Paulo: Perspectiva, 2004.

GOULART, M. S. B.; DURÃES, F. A reforma e os hospitais psiquiátricos: histórias da desinstitucionalização. Psicologia e Sociedade. v. 22, n. 1, 2010.

GUIMARÃES, T. A. A.; ROSA, L. C. S. A remanicomialização do cuidado em saúde mental no Brasil no período de 2010-2019: análise de uma conjuntura antirreformista. O Social em Questão, n. 44, 2019.

LEITE, L. S.; ROCHA, K. B. Educação permanente em saúde: como e em que espaços se realiza na perspectiva dos profissionais de saúde de Porto Alegre. Estudos de Psicologia, v. 22, n. 2, 2017. 


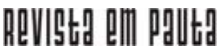

\} O CUIDADO DO HOSPITAL - ARRUDA, A.; BRASIL, M.; ARAÚJO, T.; MARTELLI, P. \}

DOI: $10.12957 /$ REP.2022.63444

MAIA, A. I. A política de saúde mental em Recife: caminhos da desinstitucionalização. Dissertação (mestrado em Serviço Social) - Universidade Federal de Pernambuco, Recife, 2007.

MEDEIROS, G. T. et al. Educação permanente em saúde mental: relato de experiência. Interface: Comunicação, Saúde, Educação, v. 20, n. 57, 2016.

MIELKE, F. B. et al. O cuidado em saúde mental no Caps no entendimento dos profissionais. Ciência e Saúde Coletiva, v. 14, n. 1, 2009.

OLIVEIRA, J. R. Políticas públicas de saúde mental e reforma psiquiátrica em Pernambuco (1991-2001). Dissertação (mestrado em História) - Universidade Federal de Pernambuco, Recife, 2008.

PITTA, A. M. F. O que é reabilitação psicossocial no Brasil, hoje? São Paulo: Hucitec, 1996.

PITTA, A. M. F. Um balanço da reforma psiquiátrica brasileira: instituições, atores e políticas. Ciência e Saúde Coletiva, v. 16, n. 12, 2011.

REIS, C.; GUARESCHI, N. Encontros e desencontros entre psicologia e política: formando, deformando e transformando profissionais de saúde. Psicologia, Ciência e Profissão, v. 30, n. 4, 2010.

SCAFUTO, J. C. B.; SARACENO, B.; DELGADO, P. G. G. Formação e educação permanente em saúde mental na perspectiva da desinstitucionalização (2003-2015). Com. Ciências Saúde, v. 28, n. 3/4, 2017.

SILVA, A. P. Caracterização da Rede de Atenção Psicossocial do Recife e sua interface com a regulação em saúde. Dissertação (mestrado em Saúde Coletiva) - Universidade Federal de Pernambuco, Recife, 2015.

SOUZA, F. S. P.; JORGE, M. S. B. O retorno da centralidade do hospital psiquiátrico: retrocessos recentes na política de saúde mental. Trabalho, Educação e Saúde, v. 17, n. 1, 2019.

ZGIET, J. Reforma psiquiátrica e os trabalhadores da saúde mental - a quem interessa mudar? Saúde em Debate, v. 37, n. 97, 2013.

DOI: $10.12957 /$ rep.2022.63444

Recebido em 24 de junho de 2021.

Aprovado para publicação em 03 de setembro de 2021.

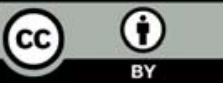

A Revista Em Pauta: Teoria Social e Realidade Contemporânea está licenciada com uma Licença Creative Commons Atribuição 4.0 Internacional. 